\title{
The Effects of Health Promotion Model on Preventive Behaviors of Osteoporosis during Premenopausal Period in Employed Women: A Quasi-experimental Study
}

\author{
Mahsa Askarian $^{1}$, Iran Jahanbin ${ }^{1}$, Fatemeh Vizeshfar $^{2 *}$, Zahra Yazdanpanahi $^{3}$, Hamideh Mohseni $^{1}$
}

\begin{abstract}
Objectives: Osteoporosis is one of the major problems of the healthcare system and is a common debilitating metabolic disease among women. Pender's health promotion model which is a conceptual framework and describes a wide range of health behavior was selected to assess the behavioral changes in this study.

Materials and Methods: A total of 122 women aged between 30 and 45 were selected to take part in this quasi-experimental study. The samples were split into experimental and control groups using the block randomization method (block size of 4). The educational program, based on Pender's model, was performed weekly. Pender's questionnaire on preventive behaviors of osteoporosis was filled out before and two months after interventions by both groups. SPSS software version 18.0 was used for data analysis.

Results: In terms of qualitative and quantitative data (demographic characteristics), there was no meaningful difference between the two groups $(P>0.05)$. The mean difference $(\mathrm{MD})$ in the score of the perceived benefits and barriers, perceived self-efficacy, programming, competing demand, and their commitment to a plan of actions increased in the experimental group after the intervention $(P<0.001)$. However, there was no significant increase in the mean score of social support in the experimental group after the intervention $(P>0.05)$.

Conclusions: It can be assumed that teaching preventive behaviors of osteoporosis through Pender's health promotion model was effective. Considering the findings, it is obvious that continuing this program can maintain and consolidate the changes which have been made in behaviors.

Keywords: Women, Health promotion, Human, Osteoporosis, Pre-menopause
\end{abstract}

\section{Introduction}

Osteoporosis is one of the major problems of the healthcare system and is a common debilitating metabolic disease among women and has been called the disease of the century by many researchers (1). The World Health Organization (WHO) declared that osteoporosis, heart attack, stroke, and cancer are the main threats to the lives of human beings $(2,3)$. Additionally, osteoporosis is called a "silent disease" as it is known to be asymptomatic until fractures occur. One of the preventive methods against this disease is raising people's awareness of its control and treatment. Fractures can be prevented by early detection and proper care and treatment of this disease $(4,5)$.

Based on previous studies in the United States, about 12000000 people aged over 50 had osteoporosis and almost 40000000 people experienced bone mass reduction at the end of 2010. It is expected that the mentioned numbers would probably increase up to 14000000 and 47000000 by 2020 for osteoporosis and mass reduction, respectively (6).

Larijani reported that about 7 million of the 70 million Iranians are at risk of fracture. The Gland and Metabolism Research Center of Tehran University of Medical Sciences reported that among those above 50 years of age, roughly $70 \%$ of women and half of men suffer osteoporosis or bone mass reduction (7).

The number of women who suffer from osteoporosis is more compared to men (8). Women make up 50\% of the world's population and they are the core of power in the family, therefore, meeting their health needs is of great importance (9). Based on this fact, when talking about energy and dynamism in the family, women's health would be reflected in the society. Based on this concept, it is vital that factors which lead to physical and emotional problems in women are identified and strategies to prevent them are also determined in order to improve the health status of women, families or communities (10). Muscle strength in women declines slowly, but around the menopausal period, following the reduction in the production of estrogen and progesterone, this loss of muscle strength becomes intensified (11-13). Peak bone mass is attained at about 30 years of age. With aging, however, the depletion in bone tissue increases and bones become weaker, bearing in mind that bone loss starts gradually (14). Therefore, the stage before menopause in women starts at the age of 35 to 39 and it can continue

Received 31 July 2018, Accepted 19 October 2018, Available online 8 December 2018

${ }^{1}$ Department of Community Health, School of Nursing and Midwifery, Shiraz University of Medical Sciences, Shiraz, Iran. ${ }^{2}$ Department of Nursing and Midwifery, Faculty of Nursing, Shiraz University of Medical Sciences, Shiraz, Iran. ${ }^{3}$ Department of Midwifery, School of Nursing and Midwifery, Shiraz University of Medical Sciences, Shiraz, Iran.

*Corresponding Author: Fatemeh Vizeshfar, Email: vizeshfarf@sums.ac.ir 
for 5 to 15 years. The incidence of vasomotor symptoms, severe bleeding, severe premenstrual syndrome, mood swings, osteoporosis, and breast cancer are the complaints before or during menopause $(15,16)$.

In 1986, the WHO defined the concept of health promotion as empowering people in order to increase control over their health and improve their lives (17). Pender stated that health promotion is an activity which enhances the level of well-being in people or groups (18).

\section{Rationale}

In this study, Pender's model was used for evaluating preventive behaviors of osteoporosis. This model is an important conceptual framework to describe a wide range of health behaviors.

This model has its roots in the theories of social cognition, nursing, and public health. It shows that people interact with their physical and interpersonal environment while trying to improve their health. The proper way of promoting healthy behaviors is a complex process affected by several variables. Pender's Health Promotion Model consists of 3 groups of factors:

- Personal characteristics and previous experience of the individual (personal factors, biological, psychological and social characteristics, and previous experience of the individual in relation to the desired behavior)

- Factors affecting specific behaviors such as cognitive and emotional feeling attached to them (the perceived benefits and barriers to perform a specific behavior, perceived self-efficacy, emotional feeling towards a behavior, and the effect of interaction with others such as families, friends, social patterns and supporting others as well as the influence of the location and time)

- The substituted activities for desired behaviors (activities that a person has little control over such as job and family responsibilities or the substituted behaviors which can be controlled by the person and has a chance of selection) (19).

\section{Objectives}

According to studies, little attention has been paid to preventive behaviors of osteoporosis before menopause based on Pender's Health Promotion Model. Previous studies mostly have concentrated on people's lifestyles or exercises based on this model. Hence, we decided to investigate the effect of Pender's health promotion model on preventing behaviors of osteoporosis before menopause in women in 2015.

\section{Methods}

This quasi-experimental study with a control group was conducted using Health Promotion Model. It was registered in the Iranian Registry of Clinical Trials (identifier: IRCT201405267531N9; https://www.irct.ir/ trial/8035).

The participants were employed women between 30 to 45 years of age. The inclusion criteria were: a) absence of menopausal symptoms in the past six months; b) no longterm use of corticosteroids; c) non-surgical removal of the ovaries; d) participation in at least 2 training classes.

The main purpose of this study was to compare the mean score of preventive behaviors of osteoporosis in both experimental and control groups. Regarding the mean difference $\left(\mathrm{m}_{1}-\mathrm{m}_{2}\right)$ of 1.3 , standard deviation (SD) of 2.5 , power $(1-\beta)$ of $80 \%$ and significance level (a) of 0.05 , almost 59 females were considered for each group. Considering the possibility of a $10 \%$ reduction in participants, the number of women was increased to 65 $(n=65)$.

Regarding the ethical issues, the researcher obtained a recommendation letter from the authorities of Fatemeh College of Nursing and Midwifery and then presented it to the central building of this university in order to receive permission. Moreover, this study was approved by the Ethics Committee.

Accordingly, to achieve the main goals of this research, the following steps were taken for sampling:

First step: 130 women were selected randomly from all employed women who aged 30-45 years in the central building of Shiraz university of Medical Sciences.

Second step: Then, using the block size of 4 , they were organized into experimental $(n=65)$ and control $(n=65)$ groups. The number of women in the experimental group decreased from 65 to 60 women and it dropped from 65 to 62 women in the control group.

Third step: After explaining the goals and benefits of this research to the women, consent form and the part of the questionnaire related to demographic characteristics were filled out by both groups.

Fourth step: After the pre-test, 3 educational classes were held for the experimental group (one session per week) in the central building of Shiraz University of Medical Sciences. Additionally, an educational pamphlet which included proper behaviors against osteoporosis was given to them. Those classes were about preventive behaviors of osteoporosis based on the subscales of Pender's health promotion model including appropriate nutrition, regular exercise, getting exposed to sunrise, and using calcium tablets.

According to the goals, the employed women were instructed in the vital behaviors which were highly beneficial for preventing osteoporosis.

Fifth step: The questionnaire of "preventive behaviors of osteoporosis" was designed based on Pender's Health Promotion Model and was filled out by both groups 2 months after the training classes.

\section{Questionnaire}

The questionnaire consisted of 2 parts.: The first part (demographic characteristics) was developed to measure 
age, education, marital status, number of pregnancies, number of children, height, weight, body mass index (BMI), osteoporosis background in the family members, hypothyroidism or hyperthyroidism, oophorectomy, history of corticosteroid usage (hydrocortisone, dexamethasone, etc), supplementary calcium usage, smoking history, regular exercise (3 times a week), and daily exposure to direct sunshine. Further, the second part of the questionnaire included six subscales based on Pender's Health Promotion Model.

Part 1: Perceived benefits and barriers subscale was presented in 12 items. Items 1 to 5 were related to the benefits and the answers were evaluated based on a 4-point Likert scale: Completely Agree (4 scores), Agree (3 scores), Disagree (2 scores) and Completely Disagree (1 score). On the other hand, items 6 to 12 were related to the barriers of preventive behaviors of osteoporosis subscale and the answers were assessed using a 4-point Likert scale (which was completely opposite to the rating scale of perceived benefits): Completely Agree (1 score), Agree (2 scores), Disagree (3 scores) and Completely Disagree (4 score). Part 2: The assessment was made based on a 3-point rating scale for perceived self-efficacy subscale consisting of 7 items: Completely Sure (3 scores), Somewhat Sure (2 scores), and Not Sure (1 score). Part 3: The programming subscale was comprised of 5 items: Often (3 scores), Sometimes (2 scores) and Never (1 score). Part 4: The evaluation of the other subscales was as follows: a 2-point rating scale for the competing demand with 4 items: True (1 score) and False (zero score). Part 5: a 3-point rating scale for the commitment to a plan of action: Often (3 scores), Sometimes (2 scores) and Never (1 score). Part 6: a 3-point rating scale for social support with 5 items: Often ( 3 scores), Sometimes (2 scores) and Never (1 score). Eventually, the total scores of the subscales were calculated for each individual.

\section{Validity and Reliability of the Questionnaire}

Content and face validity were evaluated by ten specialists in the field at Shiraz University of Medical Sciences. They also assessed the content validity index (CVI) and content validity ratio (CVR) of this questionnaire. For assessing the face validity of the questionnaire, we requested the specialists to write their comments on the place of each item, accurate scaling and grammatical structure of each item, and also the importance of adding new items or removing existing items. Finally, the face validity of the scale was determined based on an impact score of $\geq 1.5$ for all items. Regarding content validity, we requested the specialists to review all parts of the questionnaire and assess each item based on four standard criteria including relevancy, clarity, simplicity, and necessity. CVR was determined using the formula: $C V R=\left(n_{E}-N / 2\right) /(N / 2)$. Lawshe's table was used to determine the cut-off point for CVR (20). Based on Lawshe's table, the minimum CVR value required for each item was 0.62 . The CVR value for each item in this questionnaire was between 0.66 and 1. The CVI was also calculated using Waltz and Bausell method (21). Through dividing the number of specialists who ranked the items as compatible or full compatible for each criterion (relevancy, clarity, and simplicity) by the total number of specialists, CVI was achieved for each item. The average score of 3 criteria was used as the total CVI for each item. The minimum CVI value required for each item was 0.79 (22). For this scale, it was reported to be $0.9-1$ for each item and the S-CVI/Ave was reported to be 0.9 for this questionnaire. In order to assess the reliability of the questionnaire, through convenience sampling method, 130 employed women (30-45 years old) participated in a pilot study based on the inclusion and exclusion criteria. Cronbach's alpha coefficient for the second part of this questionnaire (total score) was 0.724. Therefore, the questionnaire entitled "preventive behaviors of osteoporosis based on Pender's Health Promotion Model" had a good reliability and validity.

Data analysis was performed using SPSS software version 18.0. Descriptive statistics including the frequency, percentage, mean and standard deviation were calculated. In addition, analytical data were computed for comparing qualitative variables between the 2 groups using chi-square and Fisher test. Moreover, independent $t$ test was applied to compare the differences in quantitative variables such as age and BMI and compare the mean scores of subscales of the health promotion model between experimental and control groups before and after the training. Further, paired $t$ test was applied for comparing the mean scores of subscales separately in each group before and after the training. Finally, covariance analysis was used to compare the differences between the 2 groups before training in commitment subscale.

\section{Results}

Totally, 122 women aged 30 to 45 were studied (Figure 1). Independent $t$ test was used to compare the demographic characteristics (age, height, weight, BMI, etc) of both experimental and control groups. The results showed that there was no significant difference in terms of these characteristics between the 2 groups $(P>0.05)$ (Table 1).

Moreover, both groups were compared in terms of qualitative data using Chi-square and Fisher test. There was no significant difference in the other variables $(P>0.05)$ except for marital status and family history of osteoporosis, i.e. the 2 groups were similar (Table 2).

The independent $t$-test indicated no significant difference in the mean score of the perceived benefits and barriers, perceived self-efficacy, planning, competing demand, and social support for preventive behaviors of osteoporosis before the intervention $(P>0.05)$. However, the mean score of commitment revealed a significant difference $(P<0.05)$. Covariance analysis after adjustment of the scores of commitment before intervention showed that the difference between the scores of both groups was 


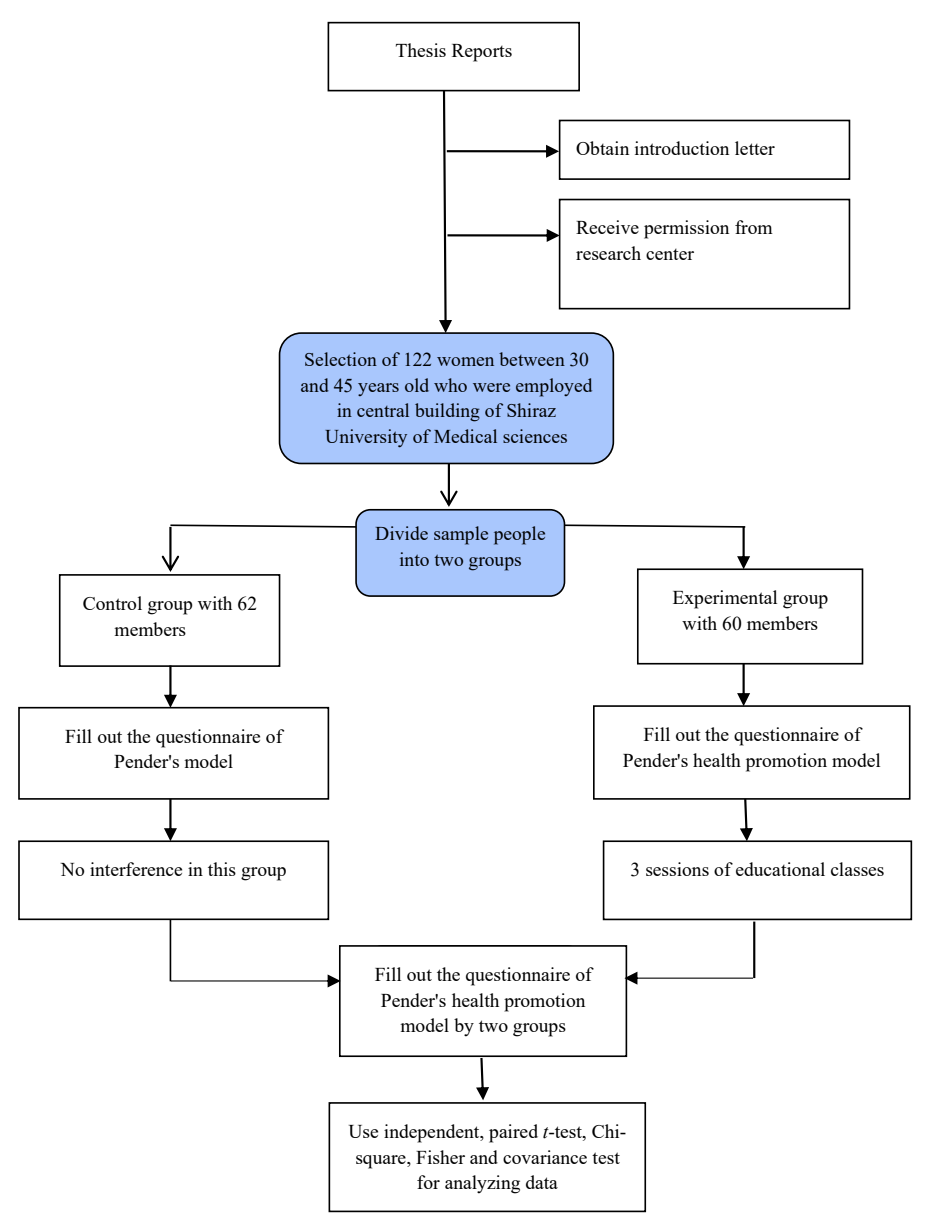

Figure 1. Flowchart of the Study Procedure.

statistically significant $(P<0.001)$ (Table 3$)$.

Further, independent $t$-test demonstrated that there is a significant difference between the mean score of the perceived benefits and barriers, perceived self-efficacy, planning, competing demand, and commitment after the intervention $(P<0.05)$, except for social support $(P>0.05)$ (Table 4).

The paired $t$-test measured the mean score of the sixth subscales of this questionnaire before and 2 months after the training separately in each group. It indicated that there was a significant difference in the mean score of the

Table 1. Comparison of the Demographic Characteristics in Experimental and Control Groups

\begin{tabular}{lccl}
\hline \multirow{2}{*}{ Variable } & \multicolumn{2}{c}{ Group } & \\
\cline { 2 - 3 } & $\begin{array}{c}\text { Experimental }(\mathrm{n}=62) \\
(\text { Mean } \pm \text { SD) }\end{array}$ & $\begin{array}{c}\text { Control }(\mathrm{n}=60) \\
\text { (Mean } \pm \text { SD) }\end{array}$ & $P$ Value \\
\hline Age & $37.38 \pm 4.52$ & $37.58 \pm 4.37$ & 0.8 \\
Pregnancy & $1.18 \pm 0.86$ & $1.14 \pm 1.04$ & 0.85 \\
Children & $0.93 \pm 0.86$ & $1.11 \pm 1.04$ & 0.3 \\
Height & $161.45 \pm 5.09$ & $162.40 \pm 4.07$ & 0.29 \\
Weight & $63.40 \pm 9.21$ & $63.95 \pm 7.26$ & 0.71 \\
BMI & $24.35 \pm 3.65$ & $24.29 \pm 2.98$ & 0.92 \\
\hline
\end{tabular}

Table 2. Comparison of the Qualitative Data in Experimental and Control Group

\begin{tabular}{|c|c|c|c|c|c|}
\hline \multirow{3}{*}{ Variable } & \multicolumn{4}{|c|}{ Groups } & \multirow{3}{*}{$P$ Value } \\
\hline & \multicolumn{2}{|c|}{ Experimental $(n=60)$} & \multicolumn{2}{|c|}{ Control $(n=62)$} & \\
\hline & No. & $\%$ & No. & $\%$ & \\
\hline \multicolumn{6}{|c|}{ Osteoporosis background in family members } \\
\hline Yes & 30 & 50 & 21 & 33.9 & \multirow{2}{*}{0.224} \\
\hline No & 28 & 46.8 & 41 & 66.1 & \\
\hline \multicolumn{6}{|c|}{ Hypo or hyperthyroidism } \\
\hline Yes & 14 & 23.3 & 18 & 29 & \multirow{2}{*}{0.219} \\
\hline No & 45 & 75 & 44 & 71 & \\
\hline \multicolumn{6}{|c|}{ Oophorectomy } \\
\hline Yes & 0 & 0 & 0 & 0 & \multirow{2}{*}{0.32} \\
\hline No & 60 & 100 & 62 & 100 & \\
\hline \multicolumn{6}{|c|}{ Corticosteroids usage background } \\
\hline Yes & 16 & 26.7 & 14 & 22.6 & \multirow{2}{*}{0.52} \\
\hline No & 42 & 70 & 48 & 77.4 & \\
\hline \multicolumn{6}{|c|}{ Supplementary calcium usage background } \\
\hline Yes & 18 & 30 & 26 & 41.9 & \multirow{2}{*}{0.53} \\
\hline No & 41 & 48.3 & 34 & 54.8 & \\
\hline
\end{tabular}


Table 3. Comparison of the Subscales of Pender's Model in the Experimental and Control Groups Before Intervention

\begin{tabular}{lccc}
\hline & \multicolumn{2}{c}{ Groups } & \\
\cline { 2 - 3 } Subscales & $\begin{array}{c}\text { Experimental } \\
\text { (Mean } \pm \text { SD) }\end{array}$ & $\begin{array}{c}\text { Control } \\
\text { (Mean } \pm \text { SD) }\end{array}$ & P Value \\
\cline { 2 - 3 } & $\begin{array}{c}\text { Before } \\
\text { Intervention }\end{array}$ & $\begin{array}{c}\text { Before } \\
\text { Intervention }\end{array}$ & \\
\hline $\begin{array}{lccc}\text { Perceived benefits and } \\
\text { barriers }\end{array}$ & $39.56 \pm 4.06$ & $39.19 \pm 6.35$ & 0.69 \\
$\begin{array}{lccc}\text { Perceived self-efficiency } \\
\text { Programming }\end{array}$ & $17.18 \pm 2.65$ & $17.79 \pm 3.14$ & 0.25 \\
Competing demand & $10.05 \pm 2.15$ & $10.64 \pm 2.36$ & 0.14 \\
Commitment & $3.25 \pm 0.79$ & $3.22 \pm 1.06$ & 0.88 \\
Social support & $8.78 \pm 1.49$ & $9.41 \pm 1.51$ & 0.021 \\
\hline
\end{tabular}

Table 4. Comparison of the Subscales of Pender's Model in the Experimental and Control Groups After Intervention

\begin{tabular}{lccc}
\hline & \multicolumn{2}{c}{ Groups } & \\
\cline { 2 - 3 } Subscales & $\begin{array}{c}\text { Experimental } \\
\text { (Mean } \pm \text { SD) }\end{array}$ & $\begin{array}{c}\text { Control } \\
\text { (Mean } \pm \text { SD) }\end{array}$ & P Value \\
\cline { 2 - 3 } & $\begin{array}{c}\text { After } \\
\text { Intervention }\end{array}$ & $\begin{array}{c}\text { After } \\
\text { Intervention }\end{array}$ & \\
\cline { 1 - 3 } $\begin{array}{l}\text { Perceived benefits and } \\
\text { barriers }\end{array}$ & $42.63 \pm 4.67$ & $38.59 \pm 5.73$ & 0.001 \\
$\begin{array}{lccc}\text { Perceived self-efficiency } \\
\text { Programming }\end{array}$ & $18.76 \pm 1.85$ & $17.61 \pm 3.08$ & 0.01 \\
Competing demand & $12.23 \pm 2.10$ & $10.74 \pm 2.11$ & 0.001 \\
Commitment & $3.81 \pm 0.39$ & $3.29 \pm 0.98$ & 0.001 \\
Social support & $10.23 \pm 1.53$ & $9.50 \pm 1.49$ & 0.008 \\
\hline
\end{tabular}

experimental group after training in comparison with the control group $(P<0.001)$ (Table 5).

\section{Discussion}

As stated earlier, no significant difference was observed between the 2 groups in terms of demographic information. On the other hand, a significant increase was observed in the perceived benefits and barriers of preventive osteoporosis behaviors after the intervention. This study suggests that more women understand the benefits of preventive behaviors while a few of them understand the barriers of these behaviors in their lives. Amini et al stated that there is a certain relationship between perceived benefits and quitting smoking among the youth (23). In addition, in Australia, Fary et al stated that there was a significant relationship between perceived benefits and physical activities (24). Sharifirad et al revealed that by reducing perceived barriers, fewer teens started smoking (25). Indeed, most studies have shown the importance of perceived benefits and barriers in people's lifestyles or exercises, while the present study illustrated the significance of perceived benefits and barriers in
Table 5. Caparison of the Mean Difference in the Scores of the Subscales of Pender's Model Before and After Intervention in Experimental and Control Groups

\begin{tabular}{lll}
\hline & Groups & \\
\cline { 2 - 3 } Subscales & $\begin{array}{l}\text { Experimental } \\
(\mathbf{n}=60) \\
\boldsymbol{P} \text {-Value }\end{array}$ & $\begin{array}{l}\text { Control } \\
(\mathrm{n}=62)\end{array}$ \\
\cline { 2 - 3 } Benefits and barriers & 0.001 & $\begin{array}{l}\boldsymbol{P} \text {-Value } \\
\text { Self-efficiency }\end{array}$ \\
Programming & 0.001 & 0.18 \\
Competing demand & 0.001 & 0.48 \\
Commitment & 0.001 & 0.54 \\
Social support & 0.001 & 0.1 \\
\hline
\end{tabular}

preventive behaviors of osteoporosis.

The scores of perceived self-efficiency in the present study confirmed that its level was rather low for females to perform physical activities and have adequate calcium intake. However, after the training, the perception of females about their own self-efficacy increased significantly. The study conducted by Sedlak et al suggested that subjects in that study had a lower selfefficacy (26). In a study by Cho and Lee, there was a statistical difference in the perceived self-efficiency after intervention $(P<0.001)(27)$. Therefore, our results are in line with previous studies in this regard. Obviously, the subjects had a low level of self-efficacy during their lives and they needed to improve their perception of their own self-efficacy through effective training.

It seems that educational interventions in planning for the preventive behaviors of osteoporosis such as using calcium or doing physical activities on a regular basis were beneficial in the experimental group. Tayari also reported that planning for exercises in the experimental group increased significantly after the intervention (28).

The results indicated that training could increase competing demand in the experimental group. However, Tayari reported that there was no significant difference in the experimental group before and after the intervention in behaviors substituted with sports (28). Accordingly, the present study revealed new results in this regard based on Pender's model.

The results of the present study suggested that before training, the level of commitment was low in individuals at high risk for developing osteoporosis, however, after the training, it increased substantially. Keegan et al reported that the commitment, which was related to physical activities, can predict damage which might occur after exercise. In addition, social support, self-efficacy and perceived benefits are the most powerful predictors of commitment to exercise and physical activity (29).

Social support, as a factor associated with physical activity level, is an important determinant of these behaviors in people (30). In this study, the mean score of this subscale 
was average and indicated no considerable rise after the training. It seems that in our culture, preventive behaviors such as exercise and healthy nutrition, as part of healthy lifestyles, are not yet known. Accordingly, others do not recommend these behaviors to people. On the other hand, Cho and Lee conducted several analyses and found that the development of intervention strategies, which increase the awareness of others' culture and self-efficacy and enhance supports for immigrant women, can increase physical activity among Chinese immigrants (27). Further, Wu and Pender concluded that social support can both directly and indirectly affect the behaviors of physical activity (31). The results of other studies were incongruent with the findings of this study. Therefore, it can be concluded that if women's families are instructed as well, it is more likely to achieve similar outcomes. It can also enhance families' support to promote preventive behaviors of osteoporosis among females.

\section{Conclusions}

According to the findings of this study, it can be deduced that the design and application of Pender's health promotion model were effective and useful for preventive behaviors of osteoporosis before menopause in women. Considering the fact that a large body of research focused mostly on other parts of this model, the results of the present study are novel and different in this regard. Therefore, it is vital that people are aware of the significance of this model for behaviors which seem to prevent osteoporosis.

\section{Limitations}

The small sample size of this study was related to the few numbers of employed women who were at the age of 30-45. Moreover, since a great deal of research has been conducted mostly on other parts of Pender's model, there were few studies revealing similar results about preventive behaviors of osteoporosis by this model.

\section{Conflict of Interests}

Authors declare that they have no conflict of interests.

\section{Ethical Issues}

The ethical issues in this study involved receiving the informed consent of women in research, the approval of Shiraz University of Medical Sciences, confidentiality of data collected from women, and providing the training scheme for the control group after completion of the research. This study was derived from a Master's thesis conducted in Fetemeh College of Nursing and Midwifery. This study was approved by the Ethics Committee of Shiraz University of Medical Sciences (CT-9376-7416).

\section{Financial Support}

This research was supported by the grant provided by
Shiraz University of Medical Sciences.

\section{Acknowledgments}

The authors appreciate all officials at Shiraz University of Medical Sciences who provided us with all the necessary facilities needed for the study and all women who helped us to achieve the objectives of this study.

\section{References}

1. Sambrook P, Cooper C. Osteoporosis. Lancet. 2006;367(9527):2010-2018. doi:10.1016/s01406736(06)68891-0

2. Nejati S, Rasoulzadeh N, Sedighiyani A. The Effectiveness of Education on Prevention of Osteoporosis among High School Female Students. Journal of Hayat. 2009;15(3):5965. [Persian].

3. Vahedian-Shahroodi M, Lael-Monfared E, Esmaily H, Tehrani H, Mohaddes Hakkak HR. Prediction of osteoporosis preventive behaviors using the Health Belief Model. Iranian Journal of Health Education and Health Promotion. 2014;2(3):199-207. [Persian].

4. Aghamohammadzadeh N, Najafipour F, Bahrami A, et al. Evaluation of effective factors in decreased bone density in patients with osteoporosis and osteopenia. Journal of Gorgan University of Medical Sciences. 2009;11(2):61-67. [Persian].

5. Larijani B. Osteoporosis in Iran and the world. Jam e Jam Daily, 2005.

6. Ford MA, Bass M, Zhao Y, Bai JB, Zhao Y. Osteoporosis knowledge, self-efficacy, and beliefs among college students in the USA and China. J Osteoporos. 2011;2011:729219. doi:10.4061/2011/729219

7. Mahdi Hazavehei SM, Taghdisi MH, Saidi M. Application of the Health Belief Model for osteoporosis prevention among middle school girl students, Garmsar, Iran. Educ Health (Abingdon). 2007;20(1):23.

8. Lips P, van Schoor NM. Quality of life in patients with osteoporosis. Osteoporos Int. 2005;16(5):447-455. doi:10.1007/s00198-004-1762-7

9. Rossouw JE, Anderson GL, Prentice RL, et al. Risks and benefits of estrogen plus progestin in healthy postmenopausal women: principal results From the Women's Health Initiative randomized controlled trial. Jama. 2002;288(3):321-333.

10. Falah Hosseini K, Moghaddam M, Klander C, Blard D, Chandlez S. Women's Health From infancy to the Menopause. Tehran: Shahr Ab Publication; 2000. [Persian].

11. Borges O. Isometric and isokinetic knee extension and flexion torque in men and women aged 20-70. Scand J Rehabil Med. 1989;21(1):45-53.

12. Brooks SV, Faulkner JA. Skeletal muscle weakness in old age: underlying mechanisms. Med Sci Sports Exerc. 1994;26(4):432-439.

13. Phillips SK, Rook KM, Siddle NC, Bruce SA, Woledge RC. Muscle weakness in women occurs at an earlier age than in men, but strength is preserved by hormone replacement therapy. Clin Sci (Lond). 1993;84(1):95-98.

14. Monajjemi A. Osteoporosis. 3rd ed. Tehran: Azadmehr Publication; 2010. [Persian]. 
15. Daley A, Stokes-Lampard H, Thomas A, MacArthur C. Exercise for vasomotor menopausal symptoms. Cochrane Database Syst Rev. 2014(11):Cd006108. doi:10.1002/14651858.CD006108.pub4

16. Ferrer J, Neyro JL, Estevez A. Identification of risk factors for prevention and early diagnosis of a-symptomatic postmenopausal women. Maturitas. 2005;52 Suppl 1:S7-22. doi:10.1016/j.maturitas.2005.06.017

17. Maville C, Maville J, Huerta C. Health promotion: Past, present, and future. Australia: Delmar; 2008.

18. Pender N. Health promotion in nursing practice. Appletone \& Lange; 1990.

19. Allender JA, Spradley BW. Community health nursing: Concepts and practice: Lippincott Williams \& Wilkins; 2001.

20. Msyamboza KP, Ngwira B, Dzowela T, et al. The burden of selected chronic non-communicable diseases and their risk factors in Malawi: nationwide STEPS survey. PLoS One. 2011;6(5):e20316. doi:10.1371/journal.pone.0020316

21. Waltz CF, Bausell RB. Nursing research: design, statistics, and computer analysis. Philadelphia: FA Davis Co; 1981.

22. Plichta Kellar S, Kelvin E. Munro's statistical methods for health care research. 6th ed. Philadelphia: Lippincott Williams \& Wilkins; 2012.

23. Amini A, Tavousi M, Niknami S. The impact of an educational intervention on nutritional preventive behaviors in osteoporosis among adolescent girls. Payesh. 2014;13(5):609-619. [Persian].

24. Fary RE, Slater H, Chua J, Ranelli S, Chan M, Briggs AM. Policy-into-practice for rheumatoid arthritis: randomized controlled trial and cohort study of e-learning targeting improved physiotherapy management. Arthritis Care Res (Hoboken). 2015;67(7):913-922. doi:10.1002/acr.22535

25. Sharifirad G, Mahdi Hazavehei SM, Hasanzadeh A, Danesh A. The effect of health education based on health belief model on preventive actions of smoking in grade one, middle school students. Arak Medical University Journal. 2007;10(138):79-86. [Persian].

26. Sedlak CA, Doheny MO, Estok PJ, Zeller RA. Tailored interventions to enhance osteoporosis prevention in women. Orthop Nurs. 2005;24(4):270-276; quiz 277-278.

27. Cho SH, Lee H. [Factors associated with physical activity among Chinese immigrant women]. J Korean Acad Nurs. 2013;43(6):760-769. doi:10.4040/jkan.2013.43.6.760

28. Tayari N. The impact of group interaction on physical activity based on Pender's Health Promotion Model in female students of Shiraz University of Medical Sciences [Dissertation]. Shiraz: Shiraz University of Medical Sciences; 2006.

29. Keegan JP, Chan F, Ditchman N, Chiu CY. Predictive ability of pender's health promotion model for physical activity and exercise in people with spinal cord injuries: A hierarchical regression analysis. Rehabil Couns Bull. 2012;56(1):34-47. doi: $10.1177 / 0034355212440732$

30. Tinsley BJ, Holtgrave DR, Reise SP, Erdley C, Cupp RG. Developmental status, gender, age, and self-reported decision-making influences on students' risky and preventive health behaviors. Health Educ Q. 1995;22(2):244259.

31. Wu TY, Pender N. A panel study of physical activity in Taiwanese youth: testing the revised health-promotion model. Fam Community Health. 2005;28(2):113-124.

(c) 2019 The Author (s); This is an open-access article distributed under the terms of the Creative Commons Attribution License (http://creativecommons.org/licenses/by/4.0), which permits unrestricted use, distribution, and reproduction in any medium, provided the original work is properly cited. 